\title{
Studia
}

Валентина Г. Кульпина

(Факультет иностранных языков и регионоведения Московского государственного университета

им. М. В. Ломоносова),

Виктор А. Татаринов

(Исторический факультет Московского государственного университета им. М. В. Ломоносова)

\section{Синонимия ключевых слов \\ в системе славистической библиографии как эпистемологические рефлексы развития лингвистической терминологии}

Статья представляет собой результат библиографической работы авторов по линии Международного комитета славистов при составлении Библиограбии славистического языкознания (см., например, выпуски 2001 г. - BSJ1 и 2003 г. - BSJ2), находящейся в сфере ответственности Института славистики Польской академии наук. Нашей задачей был сбор и библиографическая обработка трудов российских ученых, которые

This is an Open Access article distributed under the terms of the Creative Commons Attribution 3.0 PL License (creativecommons.org/licenses/by/3.0/pl/), which permits redistribution, commercial and non-commercial, provided that the article is properly cited. () The Author(s) 2014.

Publisher: Institute of Slavic Studies, PAS \& The Slavic Foundation

[Wydawca: Instytut Slawistyki PAN \& Fundacja Slawistyczna] 
тематически относились к сфере славистического языкознания. Умением выделения ключевых слов из созданного научного произведения, будь то доклад на конференции, статья или монография мы хотели бы поделиться с коллегами-славистами, имея в виду также необходимость обучения этим навыкам студентов, аспирантов, всех, кто занимается научными исследованиями. Это умение необходимо и полезно для всех создателей научного текста. Возникшее в наши дни требование для каждого сдающего в печать статью выделения в ней самых главных пунктов ее тематики может стать благотворным шагом вперед в том плане, что теперь, занимаясь таким видом научной деятельности, исследователь прибегает к процедурам аналитического обобщения. При этом, отвлекаясь от частностей, он выносит свой труд на более высокий уровень абстракции, побуждая тем самым свою научную мысль и мысль своих эвентуальных читателей в направлении лингвистических обобщений. Тем не менее при выделении ключевых слов необходимо понимание их места в научной деятельности и определенный навык работы с ними.

Объектом анализа в статье являются принципы отбора единиц Словаря ключевых слов славистического языкознания (SSKJS, 1999 и е-SSKJS, 2006), составленного сотрудниками Института славистики ПАН Зофьей Рудник-Карватовой и Ханной Карпиньской. В статье освещается также прагматический срез системы ключевых слов, принципы их составления и использования в современных научных исследованиях, прежде всего в области славистического языкознания ${ }^{2}$.

Словарь от 1999 г., изданный в бумажной версии (SSKJS), содержит около 2500 ключевых слов, являющихся основой библиографических описаний трудов по славистическому языкознанию. Относительно принципов, на которых зиждется словарь, его авторы пишут следующее: „Сфера охвата словаря является результатом компромисса между стремлением к наименьшим потерям информации и необходимостью избежать информационного шума в процессе индексирования и поиска с помощью Словаря" (Rudnik-Karwatowa \& Karpińska, 1999, с. 7). В настоящее время распространение в среде библиографов и пользователей системы получила

1 Эта тематика затрагивалась нами в ходе доклада: В. Г. Кульпина, В. А. Татаринов Ключевые слова в системе славистической библиограбии и в учебном процессе на конференции „Второе Всероссийское совещание славистов” в Институте славяноведения РАН 6-7 ноября 2013 г., г. Москва. 
расширенная, электронная, версия словаря тех же авторов: Słownik słów kluczowych językoznawstwa slawistycznego na CD (e-SSKJS, 2006).

Информационно-поисковая интеллектуальная Библиографическая система славистического языкознания, получившая название iSybislaw, по-русски ее называют иСибислав, является отраслевой системой. Тип этой системы - аиерархическая система, относящаяся к так называемым плоским структурам, т.е. в ней не фиксируются ассоциативные и иерархические связи слов. Эта система строится на самых частотных терминах языкознания, в том числе славистического языкознания.

\section{1. Сущностная субстанция ключевых слов, их соотно- шение с лингвистической терминологией и с систе- мой общенаучных терминов}

По поводу сущности ключевых слов Боженна Бояр, польский специалист по информационно-поисковым системам, пишет следующее: „Простейшей формой параестественных информационно-поисковых языков является язык ключевых слов. Элементарные лексические единицы этих языков, а именно: ключевые слова, равнозначны выражениям естественного языка, являющегося базой для генерирования ключевых слов. Значение ключевых слов не дано эксплицитно, поскольку предполагается, что пользователь языка ключевых слов сам дойдет до его понимания на основе своей языковой компетенции в области соответствующего естественного языка. Предполагается также, что пользователь сам откроет принцип, что ключевые слова отражают темы документов, а не элементы внетекстовой действительности" (Bojar, 2005, c. 271). Таким образом, ключевые слова, несмотря на их ярко выраженный консубстанциональный характер, представляют собой костяк, неделимую часть информационно-поискового языка любой отрасли знаний, в данном случае - информационно-поискового языка современной славистики. Правильный подбор ключевых слов предопределяет последующую точность поиска научно релевантной информации. Соответственно, предназначение ключевых слов - обеспечение интеллектуального поиска информации по проблемам славистического языкознания, возможность с ее помощью „дойти до каждого” научного произведения, связанного 
с лингвистической славистической проблематикой. Ключевые слова славистической отрасли представляют собой информационно насыщенные структуры, предопределяющие эффективность обеспечения информационных интеллектуальных потребностей языковедов-славистов. Каждое из ключевых слов отсылает нас „К собранию документов, с которыми, согласно правилам этого языка, можно это выражение соотнести...” (Bojar, 2005, c. 249), подчеркнем, к собранию документов, а это уже нечто совсем другое, нежели реальные языковедческие объекты, которые могут быть единичны.

Ключевые слова служат адекватной рубрикации научных произведений. Они складываются в специфическую терминосистему славистического языкознания. Термины лингвистики и ключевые слова соотносятся по принципу большей частотности и понятийной направленности со стороны ключевых слов. Чтобы это соотношение выявить в полной мере, нужно осознавать, каково место ключевых слов в научной коммуникации, каковы их функции в презентации научной публикации.

Ключевые слова славистического языкознания являются представителями научных лингвистических текстов, тематики славистических научных публикаций.

Ключевые слова, будучи единицами информационно-поискового языка, представляют собой фактически места в каталоге (карточном или теперь уже чаще электронном), на которых размещается информация о данном научном произведении или само научное произведение. Поэтому на составителе ключевых слов лежит большая ответственность за их выделение из текста и „запуск” в научный обиход. От их адекватного выделения зависит в конечном счете нахождение нужной научной информации и распространение результатов научных знаний, полученных данным исследователем. Необходимо отметить стержневой характер ключевых слов, их направленность на обеспечение непосредственно процессов научного познания.

Ключевые слова можно обозначить как „представителей” лингвистической терминологии, той ее части, которая особо значима с точки зрения презентации результатов славистических исследований. В то же время ключевые слова являются частью информационно-поискового языка библиотековедческой информатики. По сравнению с лингвистической терминологией как таковой они носят надстроечный характер. Соответственно, для обеспечения эффективного поиска они должны правильно 
указывать на область исследований, представленную в научном труде (и здесь их функция сродни аннотации). Они могут включать названия научных школ и методов исследований - если в научном материале речь идет именно о них. В то же время ключевые слова должны содержать указание на язык, на котором написан труд (благодаря чему работа займет в каталоге соответствующую ячейку). Ключевые слова должны содержать также указание на язык, являющийся объектом исследования. Если работа посвящена сопоставлению двух (и более) языков, что характерно для славистических исследований, в этом случае указываются оба языка сопоставления. Если описываемых языков больше, соответственно, указываются они все.

Представляется важным рассмотреть вопрос, каково соотношение ключевых слов с общенаучной терминологией. С этой целью воспользуемся примерами из общенаучных словарей (см.: Кульпина, 2007; Татаринов, 2004). В общенаучном словаре мы находим такие, к примеру, общенаучные термины, как категория, модель, теория. Ключевые же слова, для которых общенаучная терминология является базовой, должны в любом случае подвергнуться конкретизации через обязательное указание на принадлежность языковедческой дисциплине. И таким образом, в ключевых словах современной славистики выступает не слово категория, а словосочетание языковая категория, и/или конкретно (см.: SSKJS, 1999, сс. 55-57): функииональная категория, фонологическая категория, грамматическая категория, категория количества, именная категория, классифицирующая категория, лексическая категория, морфологическая категория, категория неопределенности, категория лииа, категория рода, категория падежа и т.д.; не теория, а (см.: SSKJS, 1999, с. 95) лингвистическая теория, не просто семантика, а (см.: SSKJS, 1999, с. 90) лингвистическая семантика (по-польски, кстати, semantyka językoznawcza 'языковедческая семантика') и конкретнее - аксиологическая семантика, генеративная семантика, интерпретационная семантика, когнитивная семантика, семантика текста, семантика предложения; не изменение, а (см.: SSKJS, 1999, с. 106) языковое изменение, фонетическое изменение, изменение значения, не анализ, а (см.: SSKJS, 1999, сс. 21-22), языковой анализ или конкретно - диахронический анализ, синхронный анализ, анализ дискурса, дистрибутивный анализ, фонетический анализ, фонологический анализ, анализ формы (польс. analiza formalna), функциональный анализ, функционально-семантический 
анализ, сопоставительный анализ (особенно актуальный тип анализа для славистов), конфронтативный анализ, грамматический анализ, лексико-грамматический анализ, лексико-семантический анализ, морфемный анализ, морфологический анализ, перформативный анализ, сравнительный анализ, прагмалингвистический анализ, просодический анализ, психолингвистический анализ, семантический анализ, статистический анализ, структурный анализ, компонентный анализ, текстологический анализ, сочиолингвистический анализ, стилистический анализ и т.д., не модель, а (см.: SSKJS, 1999, с. 63) языковая модель, семантическая модель, модель смысл <> текст, словообразовательная модель, структурная модель, модель предложения.

Таким образом, не просто структура, а (см.: SSKJS, 1999, с. 90): языковая структура или более конкретно, в зависимости от тематики текста: словообразовательная структура, морфологическая структура, лексическая структура, семантическая структура, грамматическая структура, синтаксическая структура, глубокая структура, поверхностная структура, предикатно-аргументная структура. Соответственно, на языке ключевых слов выступает не система, а языковая система или более конкретно фонологическая система, лексическая система, семантическая система, словообразовательная система, синтаксическая система, не тендениия, а (см.: SSKJS, 1999, с. 95): языковая тенденция, тенденция к синтетизму, тенденция $к$ аналитизму (в польском языке выступает согласованное определение: tendencja analityczna, tendencja syntetyczna). Ведь общенаучные термины (такие, например, как закон, состав, история, аспект, универсальность, идея, иерархия, максимум, прототип) являются, собственно говоря, принадлежностью всех наук. А задача составителя ключевых слов - обозначить принадлежность именно к языковедческой отрасли, а если научное произведение обладает специфической славистической направленностью - к собственно славистическому языкознанию.

Обращает на себя внимание надстроечный характер этой терминологии, ее частеречная однотипность. Характерно, что ключевые слова обладают номинативным характером. В качестве таковых могут выступать имена существительные (прежде всего в именительном и в случае выполнения ими функции несогласованного определения в родительном падеже) и служащие их атрибутом имена прилагательные. Здесь нет глаголов, наречий (хотя эти части речи способны выступать в качестве терминов любой отрасли знания и, соответственно, 
встречаются и среди лингвистической терминологии), нет причастий, нет прилагательных отдельно от определяемых ими существительных, отсутствует оценочность, разного рода дискурсивные и модальные слова и выражения.

В ключевых словах должна быть обозначена область языкознания, к которой они относятся. При этом в них должна быть снята элементарная полисемия между собранием языковых единиц и областью знаний, которая ими занимается. В Библиографии славистического языкознания разграничение осуществляется следующим образом: фразеология как собрание фразеологизмов обозначается как фразеология 1 , а фразеология как наука о фразеологических единицах обозначается как фразеология 2. Такое деление обеспечивает точность информационно-поискового языка. Однако тем, кто не занимается составлением библиографических словарей, но должен выделить ключевые слова к своей работе, мы бы рекомендовали обозначить исследуемые языковые единицы как фразеологизм, а раздел языкознания, который ими занимается, как фразеология. И хотя из ключевых слов таким образом уйдет семантика совокупности фразеологизмов, тем не менее плюсом такой фиксации будет снятие полисемии, а это важная процедура с точки зрения рубрикации работы.

Затрагивая вопрос практики выделения ключевых слов, нельзя обойти молчанием недостатки при их установлении. Главный недостаток - это то, что в ключевые слова нередко попадают не термины, а то, что связано с тематикой вообще (например, весна, если поэт в анализируемом тексте пишет о весне) - такая практика выделения ключевых слов, разумеется, недопустима.

Подчеркнем, что важнейшее свойство ключевых слов - это их категориальность в том смысле, что ключевые слова призваны отражать важнейшие категории языкознания. При вычленении ключевых слов стоит заглянуть в словари лингвистических терминов и лингвистические энциклопедии. Частное необходимо отделить от общего, сосредоточившись скорее на обобщенном представлении о предмете научной работы. Вместо, к примеру, инфинитивные вопросы следует писать инфинитив, вместо коммуникативные функции следует употребить это же словосочетание в единственном числе: коммуникативная функиия. В данном случае мы привели гипотетические примеры, их, конечно, нет в базе данных среди ключевых слов. 
Характерная черта ключевых слов - их однословность или двусловность (в случае двусловного термина-словосочетания). Поэтому крупные терминологические сочетания необходимо при выделении ключевых слов разбить на более мелкие, двусоставные. Так, словосочетание современный русский литературный язык не может выступать в качестве ключевого слова. Развернутый характер такого словосочетания не позволяет осуществить его адекватную рубрикацию. Правильным с точки зрения презентации online будет его разнесение на отдельные словосочетания: русский язык, современный язык, литературный язык. Тогда ваша статья займет в каталоге соответствующие ячейки. Излишнее дробление тематики также не слишком показательно для будущей дистрибуции работы в ящиках (реальных или виртуальных) каталога. Если, к примеру, ваша публикация посвящена частице ли или описанию какого-либо одного диалектного слова, то название частицы или диалектное слово-предмет описания следует писать курсивом. Это для библиографа-составителя каталога знак, в какую ячейку поместить название диалектного слова или частицы.

\section{2. Синонимические аналоги внутри системы ключевых слов}

В статье авторы сочли необходимым затронуть такой аспект системы ключевых слов, как синонимические аналоги внутри системы. Без них никак нельзя обойтись, потому что ключевые слова предопределяют места, в которых научное исследование будет размещено в каталогах. Как известно, синонимы всегда акцентируют разные грани какого-то понятия. Так происходит и с терминологическими синонимами. Впрочем, в системе славистической информации iSybislaw синонимия заложена a priori, без таковой обойтись просто невозможно. В Энииклопедическом словаре информации, информационно-поисковых языков и систем (SEI, 2002) явление синонимии рассматривается как неделимая часть информационно-поисковых языков: „Явление функционирования синонимов в ${ }^{\star}$ информационно-поисковых языках носит название *поисковой синонимии”. В вышеназванном словаре в словарной статье на заголовочное слово поисковая синонимия указывается, что такой тип синонимии „имеет место на уровне *элементарных лексических единиц 
в *языке ключевых слов...” (SEI, 2002, с. 257). Таким образом, включение в Словарь ключевых слов лингвистических терминов-синонимов - это необходимость и неизбежность.

Терминосистема лингвистики является частью лексической системы языка, для которой характерно наличие синонимов, с разных сторон освещающих свойства и признаки каких-либо объектов окружающей действительности. В наши дни наличие синонимов в отраслевых терминологиях любых научных направлений является общепризнанным фактом. Без синонимических терминов не обходится ни одна терминосистема. Терминосистемы формируются под воздействием таких факторов, как необходимость обозначить какой-либо новый объект, аспект или явление. Формирование терминосистем представляет собой длительный процесс, а элементы терминосистем, то есть термины, отражают эволюцию понятий, наслоение разных факторов языковой, социокультурной, исторической, а также и ситуативной и окказионально-случайной природы. В них выражено индивидуально-личностное понимание терминов со стороны их создателей. Невозможно представить себе терминосистему какой-либо науки без наличия синонимов, отражающих разные этапы накопления знаний об объекте, различия в его понимании со стороны разных исследователей, „борьбу” создателей терминов с языковой материей, из которой, как известно, состоят термины (ср.: ОТЭС, 2006).

Не является исключением и терминосистема современного языкознания. Удачно построенный синоним говорит о лабильности категориального мышления ученого, а отсутствие синонимов в терминологии - о застое научной мысли. Надежный и адекватный словарь ключевых терминов современного славистического языкознания призван в должной мере отразить и терминологическую синонимию. Обратившись к понятийнотерминологическому аппарату современного славистического языкознания, мы обнаружим здесь в составе славистических терминов целый ряд общенаучных терминов, таких, например, как категория, модель, образеи, показатель (ПРОС, 2007) и др., приобретающих на почве языкознания свое наполнение, тем не менее в определенной степени сохраняющих свой общенаучный смысл и общенаучные синонимические связи (ср., напр., градация - иерархия, степень - мера).

В состав лингвистической терминологии входит большое количество заимствований, функционирующих наряду с так называемой исконной терминологией и кальками, которые нередко формируют синонимические 
пары. Так, например, słownictwo 'лексика' (SSKJS, 1999, с. 85) функционирует в библиографической системе iSybislaw наряду с leksyka 'лексика' (SSKJS, 1999, с. 60). В Словаре же ключевых слов эти синонимы даются как более значимый - słownictwo, и менее значимый (так как при слове leksyka дается отсылка на słownictwo') (SSKJS, 1999, c. 60); на lingwistyka arealna дается отсылка к geolingwistyka); от термина system spółgłoskowy 'система согласных' (SSKJS, 1999, с. 93) дается отсылка на konsonantyzm 'консонантизм’ (SSKJS, 1999, с. 58).

В системе iSybislaw выступает ряд терминов, строящихся из греколатинских терминоэлементов, которые нередко имеют синонимы исконного происхождения (ср., напр.: socjolekt 'социолект' (SSKJS, 1999, с. 87) gwara środowiskowa (SSKJS, 1999, с. 87: 'социолект, сленг'). Хотя термины socjolekt 'социолект' и gwara środowiskowa даются в словаре без отсылок, их синонимический характер недвузначно вытекает из их семантики и наличия контекстов с аналогичными условиями их употребления. Этапность и приращения смысла в ходе развития терминологии отражают такие, например, термины-синонимы, как forma wewnętrzna 'внутренняя форма' (SSKJS, 1999, с. 39) - тотуwaсја 'мотивация’ (SSKJS, 1999, с. 65). Синонимия ключевых слов представляет собой эпистемологические рефлексы развития лингвистической терминологии, отражая этапы научного познания и приращения научных знаний.

Есть у синонимии ключевых слов и прагматический аспект, связанный с направленностью современных словарей на пользователя и их дружественным характером как принципиально важным признаком. Дело в том, что пользователь словаря, будучи, как правило, представителем определенной школы, направления, терминологических традиций, сложившихся в данном учебном или исследовательском центре, употребляет какие-то термины, не задумываясь о том, что у данного термина имеются синонимы, которые имеют приоритет в употреблении у представителей другого научного центра или научной школы. В задачи ученого не входит мыслить до такой степени футурально, чтобы подлаживаться под эвентуально имеющий хождение термин в другой научной школе. Разумеется, любой ученый употребит именно тот термин, который для него естественен. В связи с прагматикой труда ученого синонимия ключевых слов уже по этой причине неизбежна, так как должна охватывать научные устремления не только одной какой-то школы или направления, но охватить оптимальное количество самых употребительных терминов данной отрасли, а в данном случае - терминов славистического языкознания. 
Синонимические замены могут возникать на линии иностранный термин - исконный термин. Среди ключевых слов имеется немалое количество таких прецедентов. Термины иностранного происхождения даются в Словаре с отсылкой к исконным терминам. Ср. напр.: abstractum zob. rzeczownik abstrakcyjny (SSKJS, 1999, c. 17) 'абстрактум см. абстрактное существительное'; adverbium zob. przysłówek (SSKJS, 1999, с. 17) 'адвербиум см. наречие'.

Субъективный фактор не играет тут сколько-нибудь значительной роли, однако также имеет место. Общеизвестно, что библиографии составляются людьми, а библиограф - тоже человек, имеющий свой научно-исследовательский опыт (без наличия такового и без ученой степени просто невозможно попасть в ряды составителей научной библиографии), свои представления о научном процессе и, соответственно, свои терминологические предпочтения.

Информационно-поисковая система славистического языкознания в наши дни совершенствуется, чтобы быть полностью релевантной системой интеллектуального поиска, а значит, оптимальным образом отвечать на запросы пользователя (см.: (Rudnik-Karwatowa, 2002, сc. 207-212; Bojar, 2002). A. В. Добров подчеркивает, что „чем выше значение параметра точности поиска и рубрикации, тем меньше „информационного шума”, т.е. нерелевантных результатов. Чем выше значение параметра полноты поиска, тем меньше „недоступных данных”, т.е. нерелевантных данных, не предоставляемых пользователю” (Добров, 2010, с. 228).

Важнейшей частью славистической библиографии является правильный селективный подбор ключевых слов языковедами-славистами. Словарь ключевых слов является важным атрибутом работы библиографаслависта. Авторы данной статьи хотели бы, чтобы изданный в Варшаве Словарь ключевых слов славистического языкознания был переведен на русский язык и чтобы из словаря для достаточно узкого круга библиографов он стал словарем (и учебным пособием) для широкого круга исследователей, представителей российской вузовской и академической науки, которые, подбирая ключевые слова для своих публикаций, хотели бы сверяться со словарем на предмет их верификации.

Словари ключевых слов данной отрасли должны стать непременным атрибутом библиотеки современного исследователя, более того, настольной книгой по сверке правильности конструирования ключевых слов к данной статье или научной публикации другого типа. 


\section{Источники}

BSJ1, 2001 - Bibliografia językoznawstwa slawistycznego za rok 1996 z uzupetnieniami za lata 1992-1995. Pod red. Z. Rudnik-Karwatowej; oprac. H. Karpińska, Z. Rudnik-Karwatowa przy współudziale slawistów [G. Cychun, M. Dudok, A. D. Duličenko, V. G. Kul'pina et al.] Warszawa: Slawistyczny Ośrodek Wydawniczy.

BSJ2, 2003 - Bibliografia językoznawstwa slawistycznego za rok 1997 z uzupetnieniami za lata 1992-1996. Pod red. Z. Rudnik-Karwatowej; oprac. H. Karpińska, Z. Rudnik-Karwatowa, Z. Mikos przy współudziale slawistów z krajowych i zagranicznych ośrodków naukowych [B. Antonjak, V. Avilava, M. Bjeletić, V. G. Kul'pina, [...] V. A. Tatarinov et al.] - Warszawa: Slawistyczny Ośrodek Wydawniczy.

SEI, 2002 - Słownik encyklopedyczny informacji, języków i systemów informacyjno-wyszukiwawczych. Oprac. B. Bojar. - Warszawa: Wydawnictwo Stowarzyszenia Bibliotekarzy Polskich (Nauka, Dydaktyka, Praktyka; 56).

e-SSKJS, 2006 - Rudnik-Karwatowa Z., Karpińska H., Słownik słów kluczowych językoznawstwa slawistycznego. - Warszawa: Slawistyczny Ośrodek Wydawniczy. Dostępny w: http:// www.ispan.waw.pl/cnis/slownik_slow_kluczowych.htm.

SSKJS, 1999 - Rudnik-Karwatowa Z., Karpińska H., Słownik słów kluczowych językoznawstwa slawistycznego. - Warszawa: Slawistyczny Ośrodek Wydawniczy.

НРОС, 2004 - Татаринов В. А., Немецко-русский общенаучный словарь. - Москва: Московский Лицей (Библиотека журнала «Русский Филологический Вестник»; т. 43).

ОТЭС, 2006 - Татаринов В. А., Общее терминоведение: энциклопедический словарь. Москва: Московский Лицей (Библиотека журнала «Русский Филологический Вестник»; т. 46).

ПРОС, 2007 - Кульпина В. Г.; отв. ред. В. А. Татаринов. Польско-русский общенаучный словарь. - Москва: Московский Лицей (Библиотека журнала «Русский Филологический Вестник»; т. 47).

\section{Bibliography}

Bojar, B. (2005). Językoznawstwo dla studentów informacji naukowej. Warszawa: Wydawnictwo Stowarzyszenia Bibliotekarzy Polskich. (Nauka, Dydaktyka, Praktyka; 74).

Bojar, B. (2002). Słownik encyklopedyczny informacji, języków i systemów informacyjnowyszukiwawczych [SEI]. Warszawa: Wydawnictwo Stowarzyszenia Bibliotekarzy Polskich. (Nauka, Dydaktyka, Praktyka; 56).

Rudnik-Karwatowa, Z. (2002). Język informacyjno-wyszukiwawczy dokumentacyjnego systemu językoznawstwa slawistycznego: doświadczenia z realizacji projektu. In H. Popowska-Taborska, Z. Rudnik-Karwatowa, J. Rusek, \& J. Siatkowski (Ed. Board), Językoznaw- 
stwo. Prace na XIII Międzynarodowy Kongres Slawistów w Lublanie 2003 (pp. 207-212). Warszawa: Komitet Słowianoznawstwa PAN. (Z Polskich Studiów Slawistycznych; 10).

Rudnik-Karwatowa, Z. (Ed.) (Comp. Karpińska, H., \& Rudnik-Karwatowa, Z., with Cychun, G., Dudok, M., Duličenko, A. D., Kul'pina, V. G. et al.). (2001). Bibliografia językoznawstwa slawistycznego za rok 1996 z uzupełnieniami za lata 1992-1995 [BSJ1]. Warszawa: Slawistyczny Ośrodek Wydawniczy.

Rudnik-Karwatowa, Z. (Ed.) (Comp. Karpińska, H., Rudnik-Karwatowa, \& Mikos, Z., with Antonjak, B., Avilava, V., Bjeletić, M., Kul'pina, V., [...], Tatarinov, V. A. ). (2003). Bibliografia językoznawstwa slawistycznego za rok 1997 z uzupetnieniami za lata 1992-1996 [BSJ2]. Warszawa: Slawistyczny Ośrodek Wydawniczy.

Rudnik-Karwatowa, Z., \& Karpińska, H. (1999). Słownik słów kluczowych językoznawstwa slawistycznego [SSKJS]. Warszawa: Slawistyczny Ośrodek Wydawniczy.

Rudnik-Karwatowa, Z., \& Karpińska, H. (2006). Słownik słów kluczowych językoznawstwa slawistycznego [e-SSKJS]. Retrieved December 20, 2013, from http:// www.ispan.waw.pl/ cnis/slownik_slow_kluczowych.htm

Добров, А. В. (2010). Технологии интеллектуального поиска и способы оценки их эффективности. In A. С. Герд (Ed.), Структурная и прикладная лингвистика (8th ed., pp. 219-232). Санкт-Петербург.

Кульпина, В. Г. (2007). Польско-русский общенаучный словарь [ПРОС]. (В. А. Татаринов, Ed.). Москва: Московский Лицей. (Библиотека журнала «Русский Филологический Вестник»; Vol. 47).

Кульпина, В. Г., \& Татаринов, В. А. (2004). Реф. книги: „Библиография славистического языкознания за 1996 г. с допол. за годы 1992-1995” [Bibliografia językoznawstwa slawistycznego za rok 1996 z uzupełnieniami za lata 1992-1995. Pod red. Z. Rudnik-Karwatowej; oprac. Karpińska H. et al. Warszawa: SOW, 2001. 869 s.]. Социальные и гуманитарныле науки. Отечественная и зарубежная литература, Серия 6, Языкознание (2), 19-21.

Кульпина, В. Г., \& Татаринов, В. А. (2005). Реф.: Совершенствование информационнопоискового языка в лингвистике: 1. RUDNIK-KARWATOWA Z., Język informacyjnowyszukiwawczy dokumentacyjnego systemu językoznawstwa slawistycznego (doświadczenia z realizacji projektu). In: Językoznawstwo. Prace na XIII Międzynarodowy Kongres Slawistów w Lubljanie 2003. Komitet red.: Popowska-Taborska H. et al. - Warszawa: Komitet Słowianoznawstwa PAN, 2002, s. 207-212. (Z Polskich Studiów Slawistycznych; seria 10). 2. BOJAR B., Językoznawstwo dla studentów informacji naukowej. - Warszawa: Stowarzyszenie Bibliotekarzy Polskich, 2005. 372 s. (Nauka, Dydaktyka, Praktyka; 74). Социальные и гуманитарные науки. Отечественная и зарубежная литература, Серия 6, Языкознание (3), 66-71.

Татаринов, В. А. (2004). Немецко-русский общенаучный словарь [НРОС]. Москва: Московский Лицей. (Библиотека журнала «Русский Филологический Вестник»; Vol. 43).

Татаринов, В. А. (2006). Общее терминоведение: энииклопедический словарь [ОТЭС]. Москва: Московский Лицей. (Библиотека журнала «Русский Филологический Вестник»; vol. 46). 


\section{Bibliography (transliteration)}

Bojar, B. (2005). Językoznawstwo dla studentów informacji naukowej. Warszawa: Wydawnictwo Stowarzyszenia Bibliotekarzy Polskich. (Nauka, Dydaktyka, Praktyka; 74).

Bojar, B. (2002). Słownik encyklopedyczny informacji, języków i systemów informacyjno-wyszukiwawczych [SEI]. Warszawa: Wydawnictwo Stowarzyszenia Bibliotekarzy Polskich. (Nauka, Dydaktyka, Praktyka; 56).

Dobrov, A. V. (2010). Tekhnologii intellektual'nogo poiska i sposoby otsenki ikh ėffektivnosti. In A. S. Gerd (Ed.), Strukturnaia i prikladnaia lingvistika (8th ed., pp. 219-232). Sankt-Peterburg.

Kul'pina, V. G., \& Tatarinov, V. A (2005). Ref.: Sovershenstvovanie informatsionno-poiskovogo iazyka v lingvistike: 1. RUDNIK-KARWATOWA Z., Język informacyjno-wyszukiwawczy dokumentacyjnego systemu językoznawstwa slawistycznego (doświadczenia z realizacji projektu). In: Językoznawstwo. Prace na XIII Międzynarodowy Kongres Slawistów w Lubljanie 2003. Komitet red.: Popowska-Taborska H. et al. - Warszawa: Komitet Słowianoznawstwa PAN, 2002, s. 207-212 (Z Polskich Studiów Slawistycznych; seria 10). 2. BOJAR B., Językoznawstwo dla studentów informacji naukowej. - Warszawa: Stowarzyszenie Bibliotekarzy Polskich, 2005. 372 s. (Nauka, Dydaktyka, Praktyka; 74). Sotsial'nye i gumanitarnye nauki. Otechestvennaia i zarubezhnaia literatura, Seriia 6, IAzykoznanie (3), 66-71.

Kul'pina, V. G., \& Tatarinov, V. A. (2004). Ref. knigi: „Bibliografiia slavisticheskogo iazykoznaniia za 1996 g. s dopol. za gody 1992-1995" [Bibliografia językoznawstwa slawistycznego za rok 1996 z uzupełnieniami za lata 1992-1995. Pod red. Z. Rudnik-Karwatowej; oprac. Karpińska H. et al. - Warszawa: SOW, 2001. 869 s.]. Sotsial'nye i gumanitarnye nauki. Otechestvennaia i zarubezhnaia literatura, Seriia 6, IAzykoznanie (2), 19-21.

Kul'pina, V. G. (2007). Pol'sko-russkiı̌ obshchenauchny̌ slovar' [ПРОC]. (V. A. Tatarinov, Ed.). Moskva: Moskovskiı̌ Litser. (Biblioteka zhurnala «Russkiı̌ Filologicheskiı̌ Vestnik». Vol. 47).

Rudnik-Karwatowa, Z. (2002). Język informacyjno-wyszukiwawczy dokumentacyjnego systemu językoznawstwa slawistycznego: doświadczenia z realizacji projektu. In H. Popowska-Taborska, Z. Rudnik-Karwatowa, J. Rusek, \& J. Siatkowski (Ed. Board), Językoznawstwo. Prace na XIII Międzynarodowy Kongres Slawistów w Lublanie 2003 (pp. 207-212). Warszawa: Komitet Słowianoznawstwa PAN. (Z Polskich Studiów Slawistycznych; seria 10).

Rudnik-Karwatowa, Z. (Ed.) (Comp. Karpińska, H., \& Rudnik-Karwatowa, Z., with Cychun, G., Dudok, M., Duličenko, A. D., Kul'pina, V. G. et al.) (2001). Bibliografia językoznawstwa slawistycznego za rok 1996 z uzupetnieniami za lata 1992-1995 [BSJ1]. Warszawa: Slawistyczny Ośrodek Wydawniczy.

Rudnik-Karwatowa, Z. (Ed.) (Comp. Karpińska, H., Rudnik-Karwatowa, \& Mikos, Z., with Antonjak, B. , Avilava, V., Bjeletić, M., Kul'pina, V., [...], Tatarinov, V. A. ). (2003). Bibliografia jezzykoznawstwa slawistycznego za rok 1997 z uzupetnieniami za lata 1992-1996 [BSJ2]. Warszawa: Slawistyczny Ośrodek Wydawniczy. 
Rudnik-Karwatowa, Z., \& Karpińska, H. (1999). Słownik słów kluczowych językoznawstwa slawistycznego [SSKJS]. Warszawa: Slawistyczny Ośrodek Wydawniczy.

Rudnik-Karwatowa, Z., \& Karpińska, H. (2006). Słownik słów kluczowych językoznawstwa slawistycznego [e-SSKJS]. Retrieved December 20, 2013, from http:// www.ispan.waw.pl/ cnis/slownik_slow_kluczowych.htm

Tatarinov, V. A. (2004). Nemetsko-russkiŭ obshchenauchnyı̆ slovar' [HPOC]. Moskva: Moskovskiı̌ Litseĭ. (Biblioteka zhurnala «Russkiĭ Filologicheskiŭ Vestnik». Vol. 43).

Tatarinov, V. A. (2006). Obshchee terminovedenie: éntsiklopedicheskiŭ slovar' [OTЭC]. Moskva: Moskovskiǔ Litseĭ. (Biblioteka zhurnala «Russkiŭ Filologicheskiǔ Vestnik». Vol. 46).

\section{Synonymy of keywords in the bibliographic system of the Slavic linguistics as epistemological reflexes of linguistic terminology's development}

\section{Summary}

In the article the features of keyword synonymy in Bibliographic database of world Slavic linguistics publications iSybislaw are considered. The issue of keywords in information retrieval system is examined in connection with synonymy in linguistic terminology. There are established relations between general scientific terms and keywords of Slavic linguistics. Some applied lingvodidactic and lingvopragmatic aspects of keywords' compiling are also presented.

Keywords: keyword; linguistic term; scientific term; Polish language; Russian language; scientific term; synonymy

Ключевые слова: ключевое слово; лингвистический термин; общенаучный термин; польский язык; русский язык; синонимия 